\title{
Changes in analytical characteristics of pectic substances when freezing berries
}

\author{
Irina Sobol*, Ludmila Rodionova, Ludmila Donchenko, and Albina Varyvoda \\ Kuban State Agrarian University named after I.T. Trubilin, Kalinina str., 13, Krasnodar, 350044, \\ Russia
}

\begin{abstract}
Pectin substances are valuable components of plant cells. They have properties that allow them to be used in various industries - water retaining, gel-forming and complexing abilities. The most important property that has a positive impact on human health is the complexing ability. It is the property of pectin substances to bind heavy and toxic metals, radioactive nuclides, free radicals and other toxins in insoluble complexes and remove them from the human body. Due to their complexing ability pectin substances are used in medicines aimed at reducing cholesterol in the body, prolonging the effect of drugs, reducing the body's allergic reactions to various substances. This property depends on the analytical characteristics of pectin substances and may vary depending on the type of raw material and the method of its processing. Currently, freezing is commonly used to preserve various types of fruits and berries, especially perishable ones. There are data in the literature about changes of pectin substances in various plant raw materials, but there are not enough data about changes of analytical characteristics of pectin substances during freezing and storage and their influence on the complexing ability. The article presents a study of the analytical characteristics of pectin substances contained in red and black currant berries during the process of their freezing and storage at low temperatures. Studies on their influence on the change in the complexing ability are presented.
\end{abstract}

\section{Introduction}

In today's world, public health has deteriorated considerably. According to analyses conducted by leading experts, there has been an increase in various diseases described as "diseases of civilization". Such diseases include heart disease, cancer, allergic diseases, obesity, gout, joint damage, etc. Data from the experts at World Health Organization note that many of them lead to disability, temporary loss of ability to work, irreversible and lethal outcomes [1, 2, 3].

Many diseases are associated with diet and depend on the variety and quality of food. To reduce the impact of poor-quality products, a trend towards functional foods, which

\footnotetext{
* Corresponding author: iv-sobol@mail.ru
} 
contain ingredients that help reduce the adverse impact of those processes on the human body, is currently growing and developing $[3,4]$.

Among the functional ingredients are pectins, which are plant polysaccharides found in virtually all terrestrial plants. One of the main properties of pectin substances is their complexing ability, i.e. the ability to form complexes with heavy metals, radionuclides, free radicals, drug residues and other undesirable compounds and remove them from the human body.

The complexing ability of pectin substances depends on the analytical characteristics of pectin substances and varies depending on the type of raw material. The change in the complexing ability is related to the analytical characteristics of pectin substances - the free carboxyl groups content and the degree of esterification of the carboxyl groups by methanol [3].

In addition, pectin substances are involved in important metabolic processes: they improve the absorption of magnesium and calcium in the body; exhibit a hypocholesteremic effect by binding bile acids; have a bactericidal and antimicrobial action by changing the $\mathrm{pH}$ of the intestinal environment to be more acidic; enhance the therapeutic effect or reduce the side effects of some medicines; protect the mucosa of the stomach and intestines by coating action, thus reducing inflammation. These factors are also clearly apparent in products containing pectin substances [1,4, 11, 12].

Freezing is one of the oldest ways to preserve food. In the 20th and 21st centuries, refrigeration and freezing technology developed most intensively due to the development of low-cost refrigeration solutions. It is well known that a properly conducted freezing process preserves the value of food almost completely. This has been confirmed by many researchers $[5,6]$.

The resistance of plant tissues to negative temperatures and their water retention capacity depend on the structure of pectin substances.

During rapid freezing, hydrophilic polymers like pectin substances, starch and hemicellulose do not undergo significant destructive damage; this contributes to preservation of plant cell structure and reduction of the amount of juice released during defrosting. During defrosting, there is a natural hydrolysis of protopectin, which transforms into a soluble form and exhibits high hydrophilic properties.

Experimental data on the effect of negative temperatures on the properties and analytical characteristics of pectin substances in the scientific literature are limited. For example, it is noted that during fast and slow freezing of fruit raw material there is a more complete (3-4 times) extraction of pectin substances [8, 14].

The effect of low temperatures on the viscosity, molecular weight, and complexing ability of Jerusalem artichoke pectin is described. It was noted that the qualitative characteristics changed insignificantly after freezing, and the complexing ability virtually did not change. Significant resistance of citrus and apple pectin to low temperatures has been established. The studies show a slight change in the degree of esterification and the molecular weight of the polymer (there is a slight change in the sorption capacity of pectin substances). The effect of freezing on kiwi and sea buckthorn fruits has been studied [6,7].

Studies have been conducted to study changes in pectin substances of cherry fruits during freezing. Studies have shown a decrease in the amount of pectin substances by 26$29 \%$ during long-term low-temperature storage $[8,9,15]$.

\section{Materials and methods}

The purpose of the study was to investigate changes in the analytical characteristics of pectin substances when freezing berries. 
Research objectives: to determine changes in the analytical characteristics of pectin substances during shock freezing (at minus $30{ }^{\circ} \mathrm{C}$ ) and after 6 months of storage (at minus $20^{\circ} \mathrm{C}$ ); to establish their influence on changes in the uronid component and the complexing ability of pectin substances.

The varieties of red (Natalie, Nenagliadnaia) and black (Orloviia, Pamiati Lisavenko) currants zoned in the south and central regions of Russia were chosen as objects of the study.

Red currant variety Natalie is a variety of medium maturity, obtained as a result of intervarietal crosses. The berries are large (average weight $0.7 \mathrm{~g}$ ), rounded, slightly elongated to the base, dark red in color. The seeds are small. The taste is sweet and sour. The calyx is large, does not fall off, closed. The stalk is of medium length, green, without drooping. Self-fertile variety, yield 14.8 t/ha (3.6 kg / bush), winter-hardy, high resistance to pests and diseases.

Red currant variety Nenagliadnaia is a variety of medium maturity. The berries are medium-sized (0.6-0.8 g), rounded, bright red, sour-sweet and pleasant taste. The calyx is small, open, with a medium-length pedicel. The variety is winter-hardy, high-yielding (11.3 t/ha), characterized by good self-fertility, resistant to American powdery mildew.

Black currant variety Orloviia is an early maturing variety. The berries are large (1.2 g), rounded, black, with a moderate amount of seeds, the skin is medium, the taste is soursweet, harmonious. The calyx is closed, the pedicel is thin, medium-sized, green, without drooping. The variety is winter-hardy, fast-fruiting, self-fertile, with high resistance to diseases and gull mite, suitable for machine harvesting, with an average yield of $6.9 \mathrm{t} / \mathrm{ha}$.

Black currant variety Pamiati Lisavenko is a variety of medium maturity. The berries are medium-sized (1.1-2.0 g), rounded, black, with medium-thick skin. The pedicel is short and the calyx is closed. The taste is sweet and sour, harmonious, delicate, with a welldefined flavor.

The variety is winter-hardy, drought-resistant, self-fertile, resistant to fungal diseases and gull mite, the yield is 6.1 - $19.0 \mathrm{t} / \mathrm{ha}$.

Standard and modern methods of physico-chemical analysis were used in the experimental studies. Analytical characteristics of pectin substances were determined by conductometric titration using a HANNA conductometer; complexing ability was determined by standard trilonometric titration.

Samples of red and black currant varieties were collected in the areas of their industrial cultivation at the consumer stage of maturity.

Samples of products were taken in an amount of at least three packaging units weighing at least $15 \mathrm{~kg}$ for each variety. From the selected raw materials, average samples of $3 \mathrm{~kg}$ were formed, which were distributed in three polyethylene bags weighing $1 \mathrm{~kg}$ each. Samples were placed in prepared containers supplied with datasheets, which marked the variety of sample, net weight, freezing temperature, date of storage.

The freezing process was carried out using blast chilling using special machines at minus $30^{\circ} \mathrm{C}$. Before storing and after each removal from storage, the changes in the fractional composition of pectin substances were studied. The storage was done in refrigerated chambers at minus $20^{\circ} \mathrm{C}$, the duration of storage was six months.

\section{Results and discussion}

The work [10] published earlier by the authors provides data on the assortment of raw berries under study and presents the assessment of changes in the main chemical quality indicators (dry substances, sugars, titratable acids, vitamin C) during freezing, including changes in the amount of pectin substances and their fractional composition during storage of raw fruit and berries at low temperatures. 
This work is focused on a deeper analysis of the pectin substances of berry raw materials and is aimed at studying the changes in the analytical characteristics of pectin substances during freezing and storage and their influence on the changes in the complexing ability.

The results of the studies are shown in Figures 1-4 and Table 1.

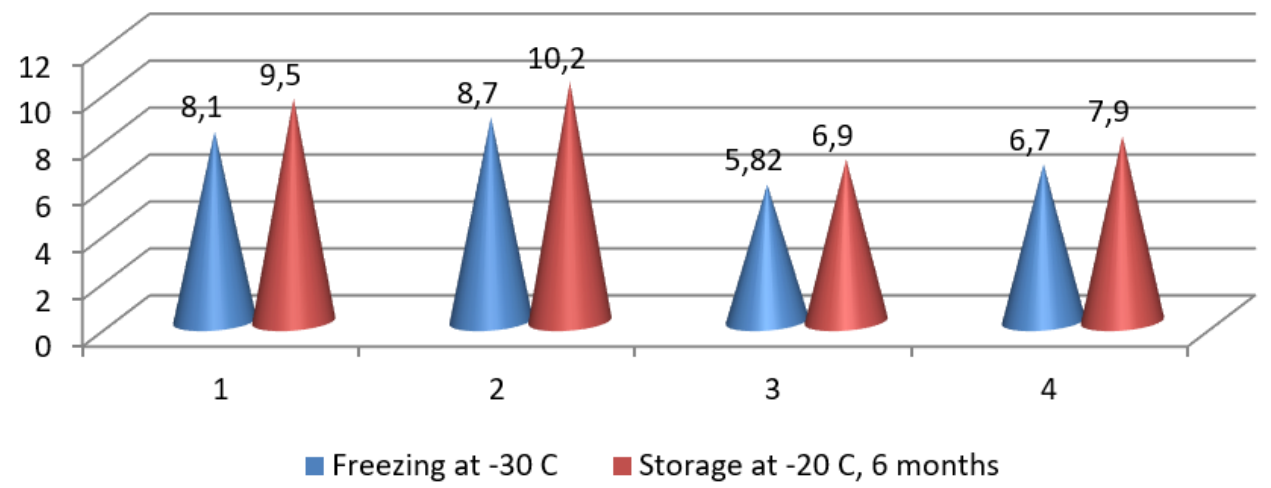

Fig. 1. The content of free carboxyl groups of pectin substances in currant varieties: 1 - red currant variety Natalie, 2 - red currant variety Nenagliadnaia, 3 - black currant variety Pamiati Lisavenko, 4 - black currant variety Orloviia

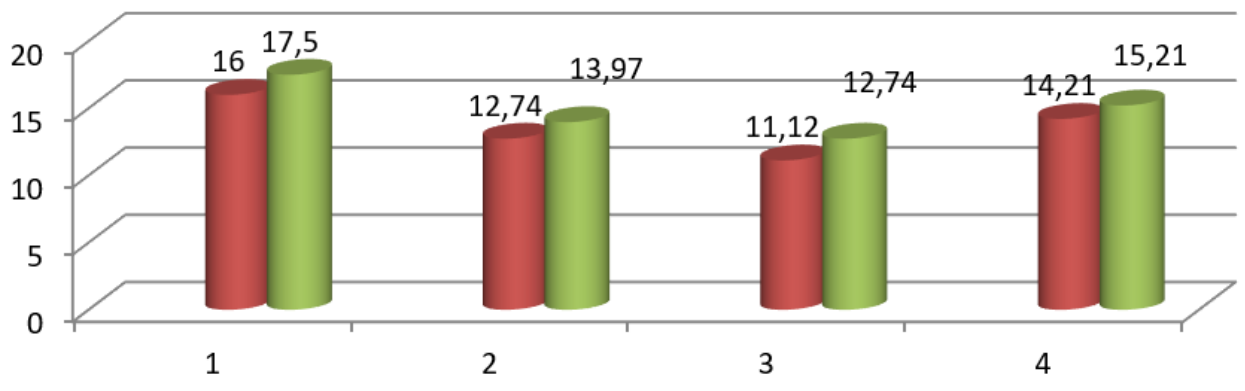

Freezing at -30 C Storage at -20 C

Fig. 2. The content of esterified carboxyl groups of pectin substances in currant varieties: 1 - red currant variety Natalie, 2 - red currant variety Nenagliadnaia, 3 - black currant variety Pamiati Lisavenko, 4 - black currant variety Orloviia

Changes in the analytical characteristics of pectin substances in the process of blast chilling and subsequent storage at minus $20^{\circ} \mathrm{C}$ for 6 months showed the following.

The content of carboxyl groups after freezing and storage increased for all samples and was $9.5 \%$ for red currant Natalie, $10.2 \%$ for red currant Nenagliadnaia, $6.9 \%$ for black currant Pamiati Lisavenko, 7.9\% for black currant - Orloviia. On average, the increase in the content of free carboxyl groups in red currant varieties was $17.3 \%$, in black currant varieties $-18.2 \%$.

A similar pattern was observed for changes in the content of esterified carboxyl groups. For red currant varieties, it was an average increase of $18.2 \%$, and for black currant varieties - by $10.8 \%$. 


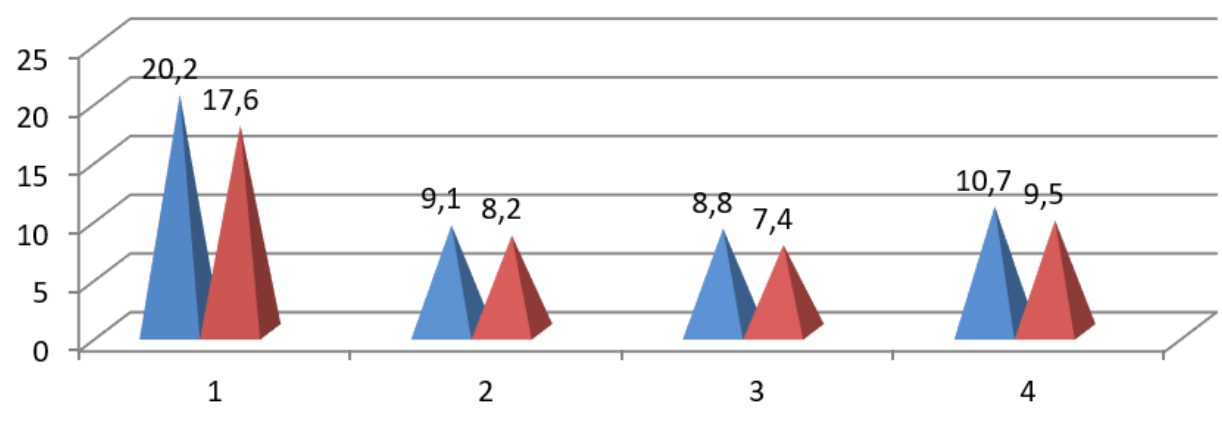

Freezing at $-30 \mathrm{C} \square$ Storage at $-20 \mathrm{C}$

Fig. 3. The content of methoxyl groups of pectin substances in currant varieties: 1 - red currant variety Natalie, 2 - red currant variety Nenagliadnaia, 3 - black currant variety Pamiati Lisavenko, 4 - black currant variety Orloviia

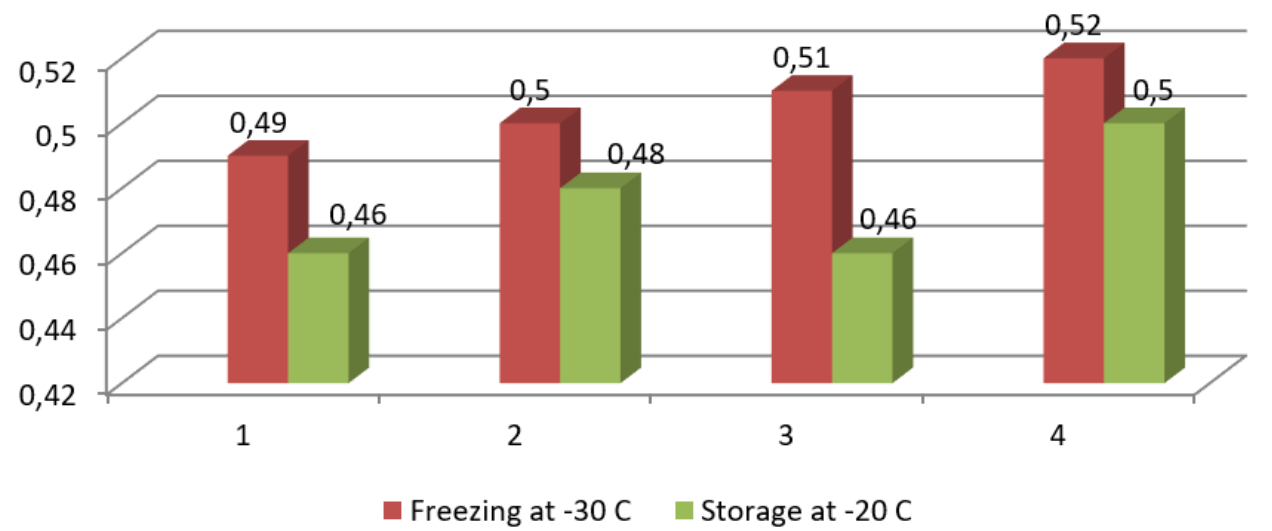

Fig. 4. The content of acetyl groups in currant varieties: 1 - red currant variety Natalie, 2 - red currant variety Nenagladnaya, 3 - black currant variety Pamiati Lisavenko, 4 - black currant variety Orloviia

Figures 3 and 4 show that the content of methoxyl and acetyl groups, on the contrary, decreased after freezing and storage. At the same time, in red currant varieties the decrease in methoxyl groups was, on average, $13.5 \%$, and the decrease in acetyl groups was $5.0 \%$. In black currant varieties, the decrease in the number of methoxyl groups was $13.6 \%$, the decrease in acetyl groups was $4.0 \%$.

Changes in the uronic component, the degree of esterification of pectin substances and complexing ability are also presented in Table 1.

Table 1. Effect of negative temperatures on the main analytical characteristics of pectin and its complexing ability

\begin{tabular}{|l|c|c|c|c|c|c|}
\hline \multirow{2}{*}{ Variety name } & \multicolumn{2}{|c|}{$\begin{array}{c}\text { Uronide component, } \\
\%\end{array}$} & \multicolumn{2}{c|}{$\begin{array}{c}\text { Degree of } \\
\text { esterification, \% }\end{array}$} & \multicolumn{2}{c|}{$\begin{array}{l}\text { Complexing capacity, } \\
\mathrm{mg} \mathrm{Pb}^{2+} / \mathrm{g} \text { of pectin }\end{array}$} \\
\cline { 2 - 7 } & $\begin{array}{l}\text { Freezing at } \\
-30^{\circ} \mathrm{C}\end{array}$ & $\begin{array}{l}\text { Storage at } \\
-20^{\circ} \mathrm{C}\end{array}$ & $\begin{array}{l}\text { Freezing } \\
\text { at }-30^{\circ} \mathrm{C}\end{array}$ & $\begin{array}{l}\text { Storage at } \\
-20^{\circ} \mathrm{C}\end{array}$ & $\begin{array}{l}\text { Freezing at } \\
-30^{\circ} \mathrm{C}\end{array}$ & $\begin{array}{l}\text { Storage } \\
\text { at }-20^{\circ} \mathrm{C}\end{array}$ \\
\hline Red currant Natalie & 68.9 & 72.4 & 67.84 & 66.58 & 121.66 & 132.89 \\
\hline Red currant Nenagliadnaia & 71.4 & 75.8 & 61.9 & 59.5 & 130.45 & 138.40 \\
\hline $\begin{array}{l}\text { Black currant Pamiati } \\
\text { Lisavenko }\end{array}$ & 78.1 & 79.2 & 68.9 & 62.5 & 100.14 & 112.23 \\
\hline Black currant Orloviia & 78.9 & 81.2 & 67.2 & 66.7 & 109.50 & 123.36 \\
\hline
\end{tabular}


The results of the study show an increase in the degree of esterification of pectin substances in red currant varieties by 3.3 points, on average, in black currant varieties - by an average of 7.5 points. The increase in pectin purity, or uronid component increased for red currant varieties by 5.5 points (on average), for black currant varieties slightly less, by 2.1 points (on average). The complex-forming ability also increased for red currant varieties (by $6.7 \%$ on average) and for black currant varieties (by $12.4 \%$ on average).

\section{Conclusions}

The results of the experimental studies showed that the complexing ability of berry crops after freezing increases. At the same time, the degree of complexing on average in pectin substances of berries increased by $10.0 \%$, the greatest increase was noted in black currant varieties - more than $12.0 \%$. This is probably due to differences in biological characteristics. Black currant berries have quite dense covering tissues, which, as a rule, are not damaged during defrosting, which is rather important when preserving berries.

Thus, it has been confirmed that an increase in carboxyl groups leads to an increase in the complexing ability. This indicates the possibility of wide use of the method of freezing and storage of red and black currant berries, in order to preserve pectin substances and slightly improve their quality characteristics.

\section{References}

1. W. J. Craig Possible mechanism through which dietary pectin influences fibrin network architecture in hypocholesterolemic subjects // Food Market \&Technology. 2009. - № 7. - P. $10-15$.

2. G. Ellen Pectin - An emerging new bioactive food polysaccharide / Ellen G., Wigel J., Keith W. Trends in Food Science \& Technology. - 2012. - № 24. - P. 64-73.

3. I. Eliaz Integrative medicine and the role modified citrus pectin alginates in heavy metal chelasion and detoxification - five case reports // Food compliments Med. 2006. - № 14. - P. 58-64

4. G. I. Freedman Functional ingredient opportunities // Trends in Food Science \& Technology. - 2012. - № 22. - P. 69-79/

5. B. M. Guseinova The nutritional value of wild fruits from the mountainous Dagestan and its preservation after rapid freezing and cold storage / B.M. Guseinova // Nutrition issues. -2016. - T. 85. - № 4.- P. 76-81.

6. W. L. Kerr Freezing effects in fruit tissue of kiwifruit observed by magnetic resonance imaging / W.L. Kerr, C.J. Clark, M.J. McCarthy, J.S. de Ropp // Scientia Horticulturae. - 1997. - T. 69. - № 3-4. - P. 169-179.

7. I. F. Korotkiy Energy efficiency analysis of the sea buckthorn (hippophae rhamnoides) fruits quick freezing / I.A.Korotkiy, E.V. Korotkaya, Kireev V.V. // Foods and Raw Materials. -2016. - T. 4. - № 1. - S. 110-120.

8. E. Vasylyshyna Content of bioactive substances in cherry fruit by different ways of freezing / E. Vasylyshyna //Carpathian Journal of Food Science and Technology. 2015.- T. 7. - № 4.- P. 36-40.

9. E. Vasylyshyna Influence of freezing and storing cherry fruit on its nutritional value/ E. Vasylyshyna //Acta Scientiarum Polonorum, Technologia Alimentaria. -2016. - T. 15. -№ 2. - P. 145-150. 
10. L. Ya. Rodionova, I. V. Sobol, L. V. Donchenko Analysis of the influence of low temperature on the change of physicochemical parameters of fruit and berry raw materials during storage / International Conference on World Technological Trends in Agribusiness //IOP Conf. Series: Earth and Environmental Science, 624 (2021) P. 1-6

11. EU 432/2012 Commission Regulation 2012 Official Journal of European Union p 40

12. T. V. Ageykina 2002 Quality of frozen fruit and vegetable products and their safety (Moscow) p. 10

13. I.A. Korotky 2009 Research and development of freezing techniques and lowtemperature storage of fruit and berry in the Siberian Region (Kemerovo: Kemerovo Technological Institute of Food Industry) pp. 20-21

14. J.A. Evans 2010 Frozen food: production and sales (St. Petersburg: Professia) pp. 250340

15. S. V. Avilova, A. A. Gruzunov and A. A. Vankova 2014 Refrigeration equipment 9 56-61 